\title{
Increased $\beta$-Nerve Growth Factor Messenger RNA and Protein Levels in Neonatal Rat Hippocampus Following Specific Cholinergic Lesions
}

\author{
Scott R. Whittemore, ${ }^{a}$ Lena Lärkfors, ' Ted Ebendal, ${ }^{1}$ Vicky R. Holets, ${ }^{2, a}$ Anders Ericsson, and Hakan Persson \\ Departments of Medical Genetics and ${ }^{1}$ Zoology, Uppsala University, S-751 23 Uppsala, Sweden, and '2Department of \\ Histology, Karolinska Institute, S-104 01 Stockholm, Sweden
}

\begin{abstract}
High levels of NGF have recently been detected in cerebral cortex and hippocampus, and it was suggested that NGF supports cholinergic, basal forebrain neurons. The present study directly examined whether NGF levels are altered in the neonatal hippocampus following cholinergic denervation by transection of the fimbria. Ten days after transection, hippocampal cholinergic innervation, as assessed by AChE histochemistry and CAT immunohistochemistry, was decreased, and both hippocampal NGF mRNA and protein were elevated about $50 \%$. This indicates possible lesioninduced transcriptional control of neonatal hippocampal NGF levels. This increase was specific to lesions of cholinergic systems, as entorhinal cortex ablation, which removes other afferent fibers to the hippocampus, did not cause a similar increase. At $30 \mathrm{~d}$ after fimbria transection, hippocampal NGF mRNA and protein did not differ from control levels, but the decrease in AChE and CAT staining persisted. Peripheral sympathectomy carried out in the adult rat resulted in 2- to 5 -fold increases in NGF protein levels in heart atrium and ventricle, as well as submandibular gland, with no concomitant increase in NGF mRNA. Therefore, the control of NGF levels in the adult PNS is probably posttranscriptional. Our results strongly suggest that NGF is involved in the regulation of central cholinergic neurons and is transiently elevated in the neonatal hippocampus following cholinergic lesion.
\end{abstract}

Neuronal development, as well as the response of the CNS to injury has been suggested to be partly mediated by the release of target-derived neurotrophic factors (Björklund et al., 1974; Cowan et al., 1984; Nieto-Sampedro and Cotman, 1985). However, identification and purification of these putative neuronal growth factors has proved difficult (Barde et al., 1983; Berg, 1984). The best characterized neuronal trophic factor is $\beta$-nerve

Received Mar. 10, 1986; revised June 10, 1986; accepted July 22, 1986.

This work was supported by the National Institutes of Health, Swedish Natural Science Research Council, Bank of Sweden Tercentenary Foundation, Swedish Medical Research Council and Kabi-Gen, Stockholm. We thank Dr. James Scott for NGF cDNA, Dr. Menek Goldstein for anti-tyrosine hydroxylase antibodics, Dr. Paul Salvaterra for anti-choline acetyltransferase antibodies, Drs. Lars Olson and Åke Seiger for invaluable discussion, and Drs. Ulf Pettersson and Tomas Hökfelt for continued support and encouragement.

Correspondence should be addressed to Dr. S. R. Whittemore at his present address.

a Present address: Department of Neurological Surgery Research Laboratories, University of Miami School of Medicine, 1600 NW 10th Avenue-R48, Miami, FL 33136.

Copyright (c) 1987 Society for Neuroscience $0270-6474 / 87 / 010244-08 \$ 02.00 / 0$ growth factor (NGF) (Levi-Montalcini and Angeletti, 1968; Thoenen and Barde, 1980). Recently, blot hybridization analysis and enzyme immunoassay detected NGF mRNA and protein preferentially in brain regions innervated by cholinergic neurons (Korsching et al., 1985; Shelton and Reichardt, 1986; Whittemore et al., 1986). While injected NGF is retrogradely transported in these adult cholinergic neurons (Schwab et al., 1979; Seiler and Schwab, 1984), the injection of NGF or anti-NGF antibodies into the adult CNS has not elicited specific alterations in cholinergic function in these areas (Gnahn et al., 1983; Hefti et al., 1984). Thus, the physiological role of NGF in the CNS remains equivocal.

The hippocampus has the highest concentration of NGF in the adult CNS (Korsching et al., 1985; Whittemore et al., 1986). The cytoarchitecture, as well as the major afferent and efferent projections of the hippocampal formation, have been well characterized (reviewed in Cotman and Nadler, 1978). The major cholinergic afferent projection is from the septal magnocellular neurons and projects to the hippocampus via the fimbria. Following fimbria transection, which removes this cholinergic innervation, as well as noradrenergic locus coeruleus and serotoninergic raphe afferents, peripheral sympathetic fibers grow into the hippocampus (Loy and Moore, 1977; Stenevi and Björklund, 1978). Crutcher et al. (1979) postulated that this sympathetic ingrowth was secondary to the release, from the hippocampus, of an NGF-like trophic factor.

Crutcher and Collins (1982) showed that the adult hippocampus, cultured in vitro, contained NGF-like activity that could be blocked by anti-NGF antibodies and that this NGF-like activity increased following medial septal lesions (Collins and Crutcher, 1985). The survival of NGF-sensitive peripheral neurons transplanted adjacent to the hippocampus was enhanced following cholinergic denervation of the hippocampus (Björklund and Stenevi, 1981; Gage et al., 1984). Similarly, striatal transplants (Toniolo et al., 1985) and basal forebrain cell suspensions (Gage and Björklund, 1986) grafted adjacent to the hippocampus showed increased CAT activity following fimbria lesions, an increase that, in the striatal transplants, was potentiated by exogenously applied NGF. Following fimbria transection, intraventricular NGF increased adult hippocampal CAT activity (Hefti et al., 1984) and promoted septal cholinergic neuron survival (Hefti, 1986). In the neonatal rat, unlike the adult, NGF injection increased CAT activity in cortex, hippocampus, septum (Gnahn et al., 1983), and striatum (Mobley et al., 1985) even without a prior lesion.

While these data suggest a role for NGF in maintaining central 
cholinergic function, endogenous NGF levels were not determined. In the present study, we directly investigated whether specific lesions that alter hippocampal cholinergic circuitry cause alterations in hippocampal NGF mRNA and protein and compared the pattern of regulation with that seen in peripheral organs following sympathetic denervation.

\section{Materials and Methods}

Surgical procedures. One-week-old Sprague-Dawley rats (Alab, Stockholm) were anesthetized with ether. Fimbria transection and entorhinal cortex ablation were performed as described by Lewis and Cotman (1980). Briefly, the fimbria was bilaterally transected by a $2-m m$-deep knife cut immediately caudal to bregma and extending $2 \mathrm{~mm}$ laterally on each side of the midline. The entorhinal cortex was ablated by suction unilaterally under a dissecting microscope. The extent of both lesions was visually assessed following removal of the brain, and only animals with complete lesions were used for further analysis. Sham-operated animals served as controls, and received a bilateral superficial knife cut through the cortex that did not injure the underlying structures. Wounds were closed with methacrylate adhesive. Animals were sacrificed 10 and $30 \mathrm{~d}$ after lesioning or sham operation.

Histological procedures. Animals were anesthetized with ether and transcardially perfused with $20 \mathrm{ml} 0.9 \% \mathrm{NaCl}$ followed by $20 \mathrm{ml} 4 \%$ paraformaldehyde and $0.4 \%$ picric acid in $0.1 \mathrm{M}$ phosphate buffer $(\mathrm{PB})$. Coronal sections $(2 \mathrm{~mm}$ ) were cut through the hippocampus, immersion postfixed in the above fixative for $3 \mathrm{hr}$, and rinsed overnight in PB containing $10 \%$ sucrose. Sections $(20 \mu \mathrm{m})$ were cut on a Leitz cryostat and processed for either the indirect immunohistochemical localization (Coons, 1958) of tyrosine hydroxylase (TH) (Markey et al., 1980) or CAT (Crawford et al., 1982) or the histochemical localization of AChE (Karnovski and Roots, 1964).

For TH localization, sections were rehydrated with $0.1 \mathrm{M}$ PBS, incubated overnight at $4^{\circ} \mathrm{C}$ with rabbit anti-TH antiserum (1:400 in PBS, $0.3 \%$ Triton $\mathrm{X}-100$ ), rinsed for $30 \mathrm{~min}$ at room temperature, and incubated for $30 \mathrm{~min}$ at $37^{\circ} \mathrm{C}$ with fluorescein-isothiocyanate conjugated (FITC) donkey anti-rabbit antibodies (1:10 in PBS, 0.3\% Triton X-100) (Amersham, Buckinghamshire). The slides were rinsed in PBS, mounted in glycerol: PBS $(3: 1)$ containing $0.3 \% p$-phenylenediamine and examined by fluorescence microscopy using a microscope equipped with a scanning dark-field condenser (Mårtenson and Björklund, 1984). Tri-X film (Kodak) was used for photography. For CAT immunohistochemistry, the sections were rehydrated with PBS, incubated for $1 \mathrm{hr}$ with PBS containing $0.3 \%$ Triton X-100, rinsed with PBS for $15 \mathrm{~min}$ at room temperature, incubated overnight at $4^{\circ} \mathrm{C}$ with mouse anti-CAT antibodics (1:20 in PBS), rinsed as above, and incubated for $30 \mathrm{~min}$ at $37^{\circ} \mathrm{C}$ with FITC sheep anti-mouse antibodies (1:10 in PBS) (Amersham). The slides were mounted, examined, and photographed as described above. Adjacent sections were processed for AChE localization, mounted as above, and examined and photographed by both bright- and dark-field microscopy.

Preparation of RNA and blot hybridization analysis. Tissues were removed and immediately frozen in liquid nitrogen. Total cellular RNA from the pooled tissue samples was prepared (Chirgwin et al., 1979) and polyadenylated $\left[\operatorname{poly}(\mathrm{A})^{+}\right]$RNA, isolated by oligo(dT) cellulose chromatography (Aviv and Leder, 1972), separated on 1\% agarose gels containing $0.7 \%$ formaldehyde, and transferred to nitrocellulose filters. The double-stranded DNA probe used to detect NGF mRNA was a 900 base pair (bp) Pst I fragment derived from a DNA clone complementary to male mouse submaxillary gland NGF mRNA (Scott et al., 1983 ) and for $\alpha$-actin, a 1.5 kilobase (kb) Pst I fragment (Minty et al., 1981). Purified DNA fragments were nick-translated, hybridized to the blotted nitrocellulose filters, and exposed on Kodak XAR-5 X-ray film as previously described (Whittemore et al., 1986). Known dilutions of poly $(\mathrm{A})^{+}$RNA from male mouse submaxillary glands were included on all gels as standards. The same filters were used for hybridization of both probes. Autoradiograms were quantified with a dual-wavelength densitometer (Shimadzu CS-930, Kyoto).

Enzyme immunoassay (EIA) for NGF. Endogenous NGF levels were determined by a sensitive fluorometric EIA (Lärkfors and Ebendal, 1987). Immunoplates ( 96 well black Microfluor plates, Dynatech) were coated with affinity-purified antibodies against mouse NGF (Stoeckel et al., 1976; Ebendal et al., 1983) and nonspecific binding blocked with $1 \%$ BSA. Tissue samples in TBS buffer [0.02 M Tris- $\mathrm{HCl}(\mathrm{pH} 7.5), 0.5$
$\mathrm{M} \mathrm{NaCl}$ containing aprotinin (20 kallikrein units/ml), $0.1 \mathrm{~mm}$ phenylmethylsulfonylfluoride, $0.1 \%$ BSA, $10 \mathrm{~mm}$ EDTA, and $0.5 \%$ Tween 20 were added to the wells and incubated for $16 \mathrm{hr}$ at $4^{\circ} \mathrm{C}$. Purified mouse $\beta$-NGF was used as a standard. Plates were washed overnight at room temperature and bound NGF mcasured using an anti-NGF-antibody- $\beta$-galactosidase conjugate and 4 -methylumbelliferyl- $\beta$-galactoside as a substrate. The reaction was followed in a Dynatech Microfluor plate reader. The subtracted background was the enzyme activity measured in parallel wells coated with the NGF antiserum immunoglobulins not absorbed by the NGF-Sepharose.

Peripheral sympathectomy. Male $150 \mathrm{~g}$ Sprague-Dawley rats (Alab) were anesthetized with ether and injected intraperitoneally with freshly prepared 6-hydroxydopamine (6-OHDA, $100 \mathrm{mg} / \mathrm{kg}$ body weight, free base in PBS containing $1.5 \mathrm{mg} / \mathrm{ml}$ ascorbic acid) or vehicle alone. All animals showed strong response (piloerection and exophthalmos) within a few minutes, and the effects persisted for $24 \mathrm{hr}$. Forty-eight hours postinjection, animals were killed by cervical dislocation; the heart atrium and ventricle and submandibular gland were removed and immediately frozen in liquid nitrogen. Tissues were then analyzed for NGF mRNA and protein.

Statistical analysis. All numerical data were analyzed with the Statistical Analysis System (SAS). Statistical significance was determined for quantitation of RNA blot hybridizations using a nonparametric 1-way analysis of variance with Wilcox score and for NGF protein with a general linear models procedure of random effects in a repeated measure design (Winer, 1971).

\section{Results}

\section{Lesion-induced alterations in hippocampal innervation}

Both AChE (Fig. 1A) and CAT (Fig. 1B) staining of control 30 d neonatal hippocampus revealed a banding pattern similar to that observed in the adult (Storm-Mathisen and Blacksted, 1964; Houser et al., 1983). A dense band of AChE-stained fibers was observed in the supragranular zone with a moderate density of fibers in the hilus and infragranular zone (Fig. $1 A$ ). A few faintly AChE-stained cell hodies were also seen in the hilus. The CATimmunoreactive fibers were very thin and formed a moderately dense band of fibers in the infragranular zone of the hilus of the dentate gyrus (Fig. $1 B$ ). Ten days after bilateral fimbria transection, the density of AChE- and CAT-positive fibers was greatly reduced in the dentate gyrus and hippocampus. This decrease persisted at $30 \mathrm{~d}$ posttransection (Fig. 1, D, E). Many AChEpositive cell bodies in the hilus were stained following fimbria transection (Fig. $1 D$ ). In contrast, $10 \mathrm{~d}$ after unilateral entorhinal cortex ablation, the ipsilateral hippocampus showed an extensive increase in the density of AChE-positive fibers, whereas only a slight increase in CAT-immunoreactive fibers was observed. No further increase in the density of CAT-immunoreactive fibers was observed $30 \mathrm{~d}$ after entorhinal cortex ablation (Fig. 1H); however, an increase in the density of AChE staining was observed in the hilus and supragranular zone of the dentate gyrus $30 \mathrm{~d}$ after entorhinal cortex ablation (Fig. $1 G$ ). No changes were observed in CAT immunoreactivity or AChE staining in the hippocampus contralateral to the lesion (data not shown).

TH immunofluorescence revealed thin, varicose fibers throughout the control dentate gyrus (Fig. 1C) and hippocampus. Ten days following bilateral fimbria transection, these thin, varicose fibers were no longer present, and instead, a few long, thick varicose $\mathrm{TH}$-immunofluorescent fibers were seen throughout the hippocampal formation. However, by $30 \mathrm{~d}$ after fimbria transection, the dentate gyrus and hilus contained many of these thick TH-positive fibers (Fig. 1F). A slight decrease in the density of TH immunoreactivity was observed in the hippocampal formation following entorhinal cortex ablation at 10 and $30 \mathrm{~d}$ postlesion (Fig. 1I), but no change in the pattern of staining was seen. 

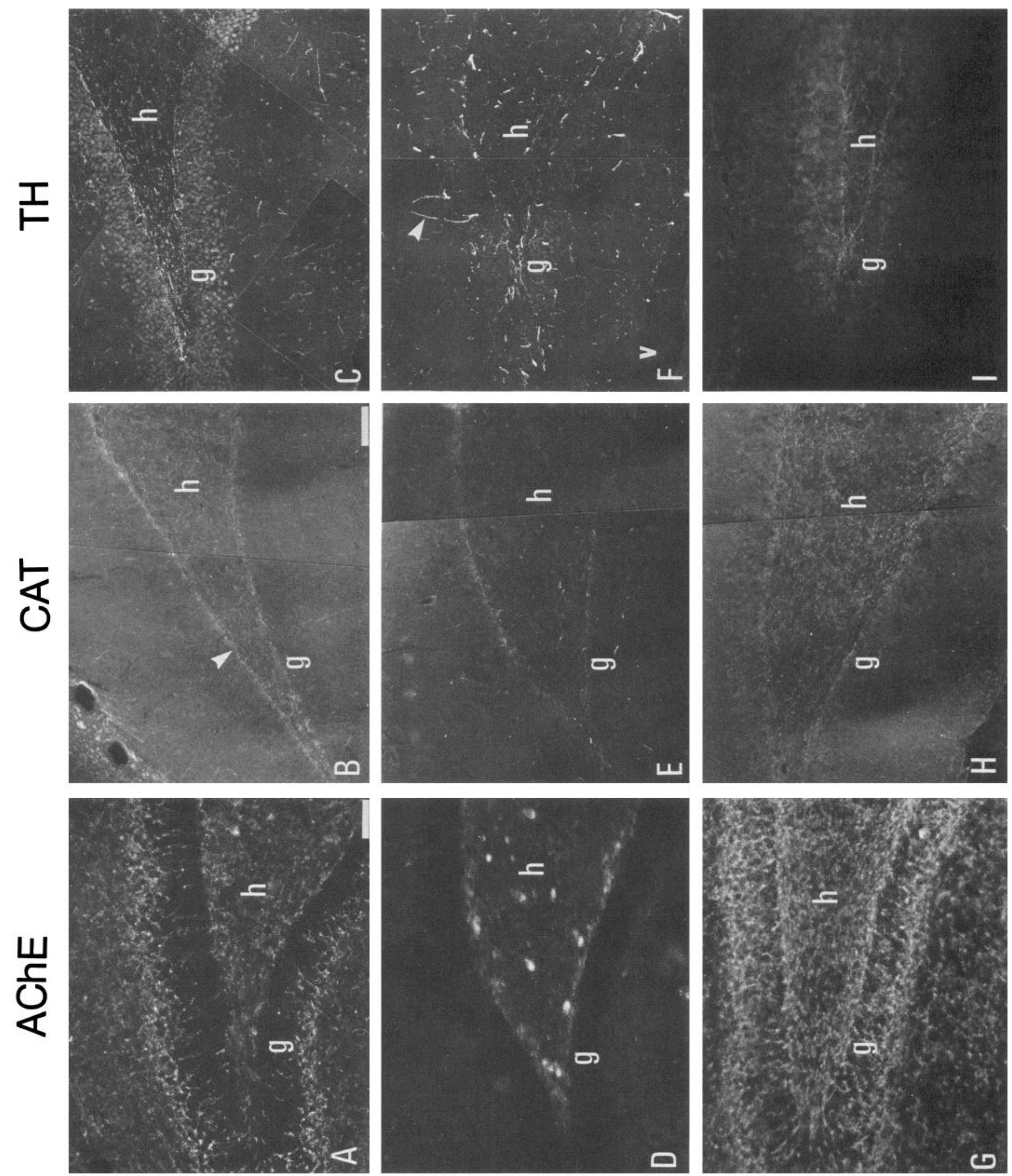

\section{占}

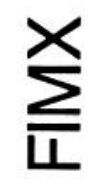

U 
A

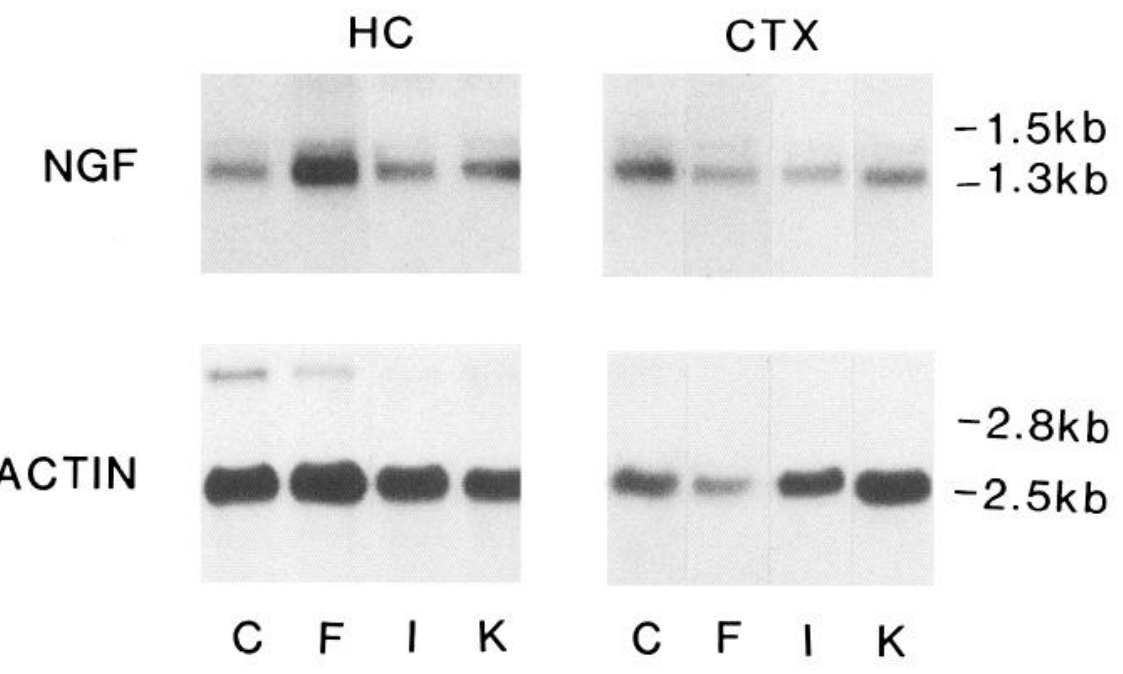

B

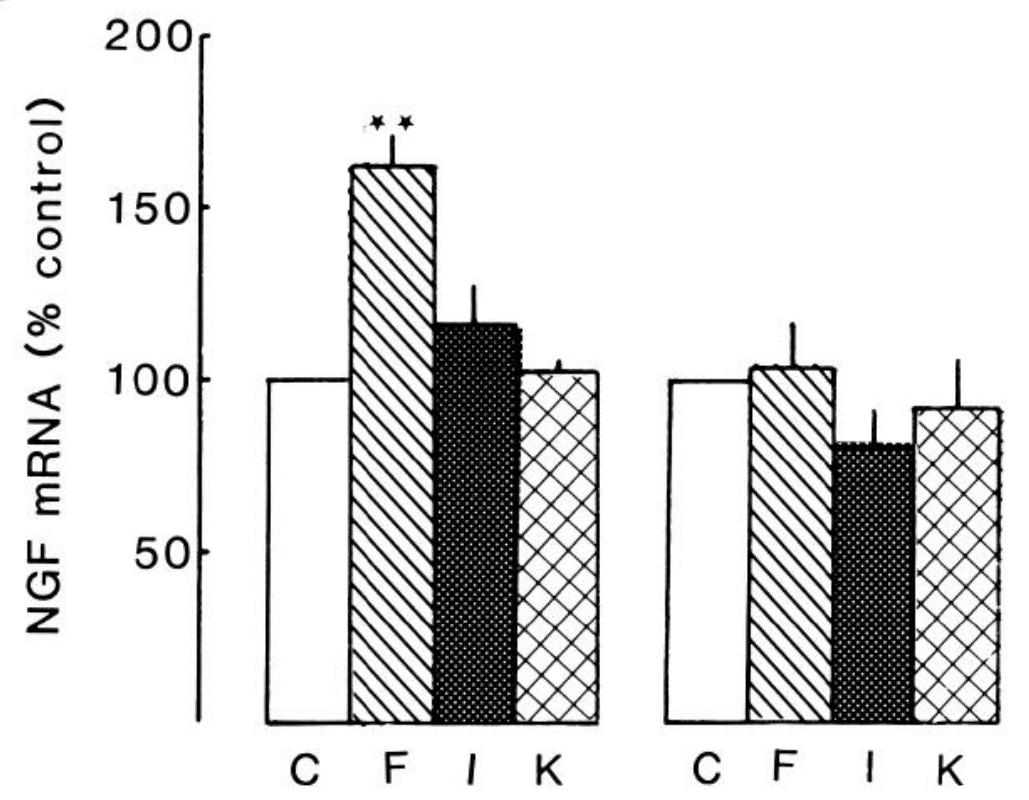

Figure 2. Lesion-induced alterations in hippocampal NGF mRNA. $A$, Poly $(\mathrm{A})^{+}$RNA $(10 \mu \mathrm{g})$ from hippocampus $(H C)$ or cortex $(C T X) 10 \mathrm{~d}$ after lesioning or sham-operation. Poly(A) ${ }^{+}$ was electrophoresed, blotted to nitrocellulose and probed with NGF and actin cDNA. The same filters were used for both probes. B, Quantitation of the relative amounts of NGF mRNA in hippocampus and cortex from $10 \mathrm{~d}$ postlesioned or sham-operated animals. Blots, generated as in $(A)$, were scanned by densitometry. Data are means \pm SEM of 4-5 experiments from 2 independent preparations of RNA, each of which was assayed at least twice. $C$, Control; $F$, fimbria transection; $I$ and $K$, ipsilateral and contralateral to unilateral entorhinal cortex ablation. ${ }^{* *} p<0.01$ compared to control; all other values were not significantly different from control.

\section{Lesion-induced alterations in NGF $m R N A$ and protein}

A $1.3 \mathrm{~kb}$ poly(A)+ NGF RNA species was detected in neonatal cortex and hippocampus (Fig. $2 A$ ), as well as in the male mouse submaxillary gland (data not shown). In addition, a $1.5 \mathrm{~kb}$ species was observed in hippocampus and cortex, which represented $20 \%$ of the hybridization signal, as seen previously in adult rat brain (Shelton and Reichardt, 1984, 1986; Whittemore et al.,
1986). Ten days after fimbria transection, hippocampal NGF mRNA levels were increased $60 \%$ above controls (Fig. 2, $A, B$ ). Identical results were obtained in 2 independent preparations of RNA. By $30 \mathrm{~d}$ after fimbria transection, NGF mRNA levels in the hippocampus were not different from age-matched controls (data not shown). In contrast, levels of NGF mRNA did not change in either the ipsilateral or contralateral hippocampus $10 \mathrm{~d}$ after unilateral entorhinal cortex lesion. A DNA probe

Figure 1. Dark-field and immunofluorescence photomicrographs of AChE histochemical staining $(A, D, G)$ and CAT- $(B, E, H)$ and TH- $(C, F$, $I$ ) immunoreactivity in the dentate gyrus of control $(C O N T)$ rats $(A-C), 30 \mathrm{~d}$ after fimbria transection $(F I M X)(D-F)$, and in the ipsilateral hippocampus $30 \mathrm{~d}$ after unilateral entorhinal cortex ablation $(E C X)(G-I)$. A, AChE staining in CONT dentate gyrus. A few faintly AChE-positive cells are seen in the hilus. $B$, CAT immunoreactivity in CONT dentate gyrus, showing a band of CAT-positive fibers in the infragranular zone (arrowhead). $C$, TH immunoreactivity in CONT dentate gyrus. $D$, No AChE staining is observed in fibers in the dentate gyrus following FIMX. Many strongly AChE-positive cells are seen in the hilus $(h) . E$, No CAT immunoreactivity is observed in the dentate gyrus following FIMX. $F$, After FIMX, the TH-immunoreactive structures in the dentate gyrus are thick and varicose (see arrowhead). $G$, An increase in the density of AChEstained fibers is seen following ECX. $H$, Slight increase in the density of CAT-positive fibers is observed in the dentate gyrus following ECX. $I$, Slight decrease in the density of TH-immunoreactive structures is seen in the dentate gyrus following ECX. $v$, ventricle; $h$, hilus; $g$, granule cell layer. Bar, $40 \mu \mathrm{m}$ in $A$ (same scale in $D, G$ ) and $50 \mu \mathrm{m}$ in $B$ (same scale in $C, E, F, H, I$ ). 

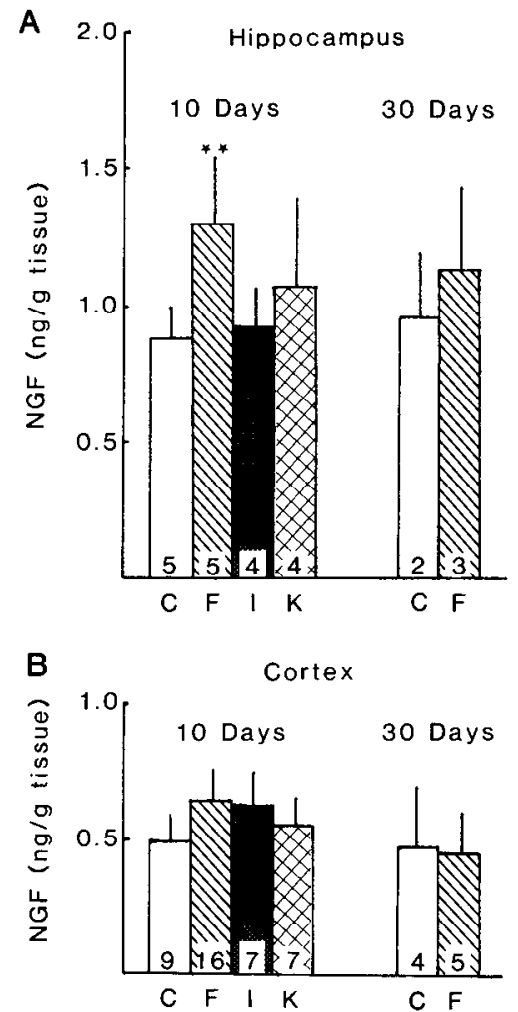

Figure 3. Lesion-induced alterations in NGF protein as detected by enzyme immunoassay. Hippocampus $(A)$ and cortex $(B) 10$ and 30 after lesioning or sham-operation. Data are the means \pm SEM of the number of independent samples indicated at the base of the bars, each of which was assayed between $5-10$ times. ${ }^{* *} p<0.01$ as compared to control; all other values were not significantly different from control. $C$, Control; $F$, fimbria transection; $I$ and $K$, ipsilateral and contralateral to unilateral entorhinal cortex ablation.

complementary to $\alpha$-actin was also used to assess the specificity of the changes in NGF mRNA levels. Actin mRNA levels did not change either in hippocampi devoid of cholinergic input or in contra- or ipsilateral hippocampi in entorhinal cortex-lesioned animals (Fig. $2 A$ ).

The levels of NGF mRNA in the cortex were also measured. No significant changes in cortical NGF mRNA expression were seen in either fimbria-transected or cntorhinal cortex-lesioned animals (Fig. 2, $A, B$ ).

NGF protein, measured by enzyme immunoassay, was detected in both neonatal hippocampus and cortex. Ten days after fimbria transection, hippocampal NGF levels had significantly increased $50 \%$, but at $30 \mathrm{~d}$ were not significantly different from the age-matched controls. In contrast, significant increases were not observed in either contra- or ipsilateral hippocampal NGF levels $10 \mathrm{~d}$ after entorhinal cortex ablation (Fig. $3 \mathrm{~A}$ ). Cortical NGF levels remained constant 10 and $30 \mathrm{~d}$ after fimbria transection or $10 \mathrm{~d}$ after entorhinal cortex lesion (Fig. $3 B$ ).

\section{Peripheral NGF $m R N A$ and protein levels following sympathectomy}

It has been shown previously that peripheral sympathectomy causes a dramatic increase in NGF levels in the denervated organs (Yap et al., 1984; Kanakis et al., 1985; Korsching and Thoenen, 1985). To determine if the peripheral regulation of NGF levels is by a similar mechanism to that seen in the CNS, adult rats were treated with 6-OHDA, sacrificed $48 \mathrm{hr}$ later and peripheral organs assayed for NGF mRNA and protein.

Following chemical sympathectomy, NGF levels increased 350,250 , and $480 \%$ in the ventricle, atrium, and submandibular gland, respectively (Fig. $4 A$ ). In contrast, the expression of NGF mRNA did not change significantly following denervation, being 92,93 , and $86 \%$ of controls in the atrium, ventricle, and submaxillary gland, respectively. Actin mRNA levels were also unchanged in the ventricle and atrium, but in the submandibular gland, sympathectomy resulted in the preferential expression of a larger actin mRNA (Fig. 4B).

\section{Discussion}

While the presence of NGF in the mammalian CNS is now unequivocal (Korsching et al., 1985; Shelton and Reichardt, 1986; Whittemore et al., 1986), its precise physiological role has not been fully elucidated. We present data that demonstrate directly that NGF levels are transiently increased in the neonatal hippocampus after lesions that remove cholinergic input.

Neonatal animals were used in this study, as they clearly show a cholinergic response to intraventricularly injected NGF, whereas adult animals do not (Gnahn et al., 1983; Mobley et al., 1985). In adult animals, the response of the hippocampus to specific lesions has been well characterized (see Cotman et al., 1981), and similar responses were now seen in the neonatal animals. Thus, fimbria transection, which removed the majority of cholinergic input, resulted in decreased AChE and CAT staining, and a concomitant change in the morphological type of THimmunoreactive fibers observed in the dentate gyrus (Fig. 1). The thick varicose TH-immunofluorescent fibers, which appeared 10 and $30 \mathrm{~d}$ after fimbria transection, probably represented peripheral adrenergic nerves, which have been observed to invade the hippocampus after such lesions in adults (Loy and Moore, 1977; Stenevi and Björklund, 1978). Consistent with this interpretation, immunosympathectomy abolishes the increase in neonatal cortical TH activity induced by NGF injection (Gnahn et al., 1983).

The major afferent innervation to the hippocampus is from the entorhinal cortex and uses excitatory amino acids as a neurotransmitter. Ablation of the adult entorhinal cortex results in massive sprouting of a number of other hippocampal afferents, including the septohippocampal cholinergic neurons (see Cotman et al., 1981). A similar response was seen in the neonate, as judged by the major increase in AChE staining. The increase in CAT immunoreactivity following entorhinal cortex ablation was not as dramatic. This discrepancy may reflect a difference in the sensitivity of the 2 procedures to detect the increase in the respective enzymes. However, a specific increase in only AChE staining cannot be excluded. While there exists extensive overlap between CAT and AChE enzyme activities, the histochemical homologies are not absolute as CAT immunohistochemistry detects fewer fibers than does AChE histochemistry (Wainer et al., 1984; Frotscher and Leranth, 1985). Based on the AChE and TH staining, the neonatal hippocampus responds similarly to specific lesions as does the adult. Thus, following fimbria transection, the cholinergic input as well as some adrenergic and serotoninergic input are removed, while after entorhinal cortex ablation, cholinergic innervation is increased.

NGF mRNA lcvels were specifically increased in the hippocampus in response to fimbria transection, as no increase was observed following entorhinal cortex lesion, which also partially 


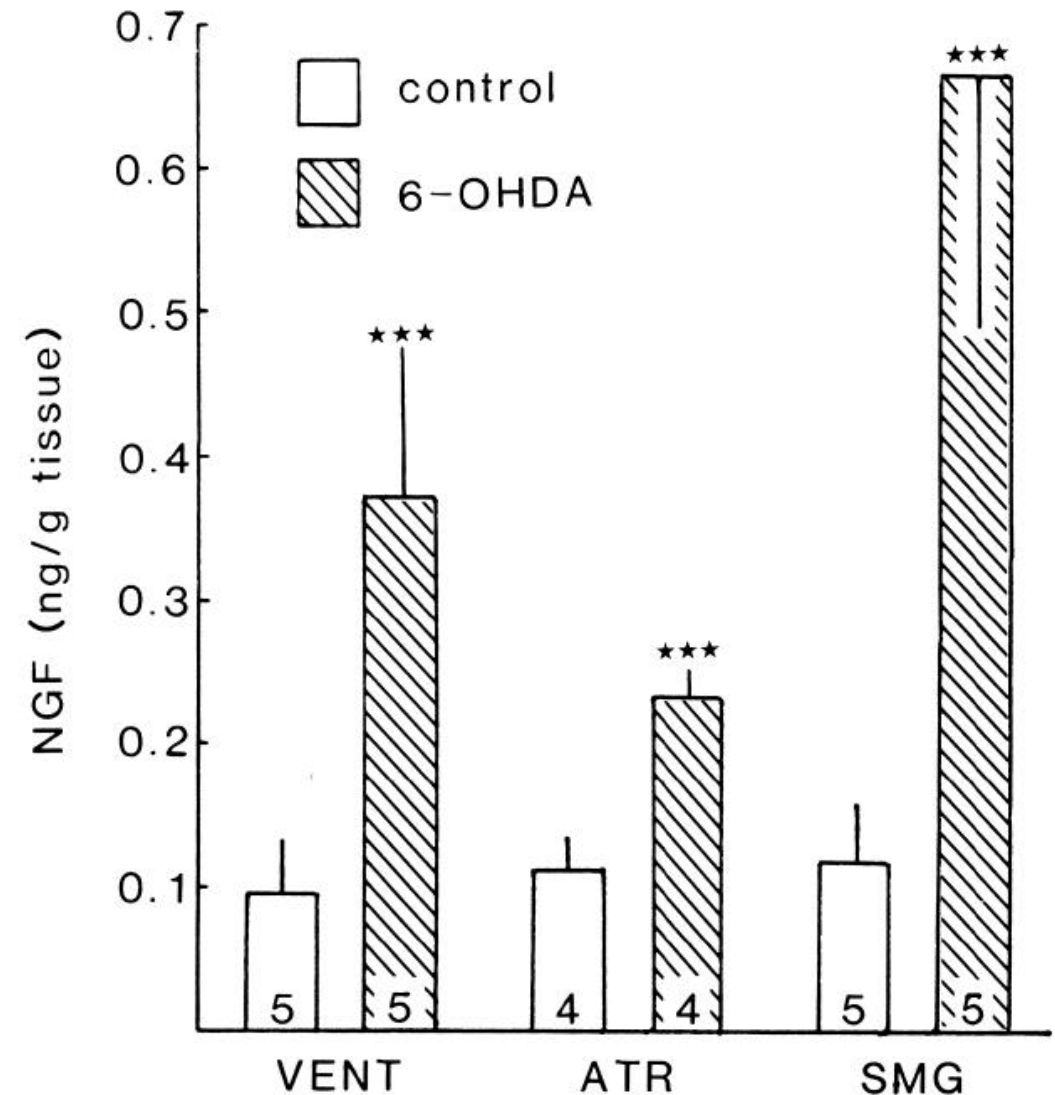

B
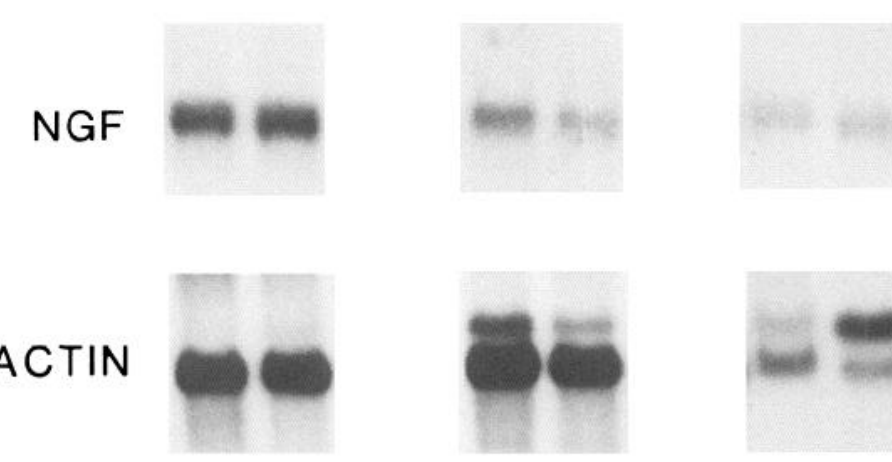

$-1.3 k b$

$-2.8 k b$
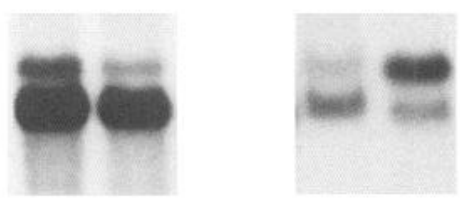

Figure 4. Peripheral organ NGF mRNA and protein levels following sympathectomy. $A$, Adult male rats treated with 6-OHDA were assayed for NGF. Values are mean \pm SEM of the number of independent samples indicated at the base of the bars, each of which was assayed 5 times. Open bars, control; hatched bars, 6-OHDAtreated. VENT, ventricle; $A T R$, atrium; $S M G$, submandibular gland. $* * * p<0.001$ compared to controls. $B$, Poly $(\mathrm{A})^{+} \mathrm{RNA}$ from samples identical to those in $A$ was electrophoresed, blotted to nitrocellulose, and probed with NGF and actin CDNA probes. The same filters were used for both probes. Quantitation of 3 experiments by densitometry showed no significant differences in NGF mRNA levels between control and drug treated animals. Identical results were obtained with another independent preparation of all 3 organs. The actin blot for SMG was exposed twice as long as those for VENT and ATR. deafferents the hippocampus (Fig. 2). Hippocampal actin mRNA levels did not change significantly following either entorhinal cortex ablation or fimbria transection, further supporting the specificity of the NGF mRNA response. The fimbria transection-induced increase in NGF mRNA was paralleled by an increase in NGF protein of identical magnitude above control levels. This response was specific to lesions that removed cholinergic input to the hippocampus (Fig. 3), consistent with previous in vitro results (Collins and Crutcher, 1985). It has been shown that cortex and hippocampus contain NGF-like protein that is physiologically indistinguishable from NGF (Whittemore et al., 1986). This, together with the present NGF mRNA data, suggests that endogenous NGF, and not an immunologically cross-reacting protein, was being measured.

The time course of the increase in NGF was similar, but slightly earlier, to that seen for lesion-induced adult hippocampal NGF-like activity (Collins and Crutcher, 1985). It is difficult to compare accurately those in vitro results with the direct measurements presented here, as Collins and Crutcher (1985) used adult hippocampal slices grown in culture to generate conditioned media and a relative index for quantitation. Injury-induced neurotrophic factors from the CNS, whose temporal appearance follows a bell-shaped curve, have been reported previously (Nieto-Sampedro et al., 1982, 1984; Manthorpe et al., 1983). Additionally, differential temporal expression of central injury-induced neuronal growth factors at various developmental stages has been observed (Needels et al., 1985; Whittemore et al., 1985).

Following entorhinal cortex lesion, a dramatic increase in AChE-positive fibers and a slight increase in CAT immuno- 
reactivity was observed, with no concomitant change in either NGF mRNA or NGF levels. If NGF is involved in the support of these presumably cholinergic fibers, the NGF already produced may be sufficient to support the additional septohippocampal axonal sprouts. Alternatively, either additional trophic factors are involved or the increased AChE- and CAT-positive fibers arise from axonal sprouting of nonseptal, NGF-insensitive cholinergic hippocampal interneurons.

We previously did not detect changes in NGF mRNA in the adult hippocampus following fimbria transection (Whittemore et al., 1986). These results have been corroborated recently (Korsching et al., 1986). Results from transplant experiments (Björklund and Stenevi, 1981; Gage et al., 1984; Toniolo et al., 1985), and in vitro studies (Collins and Crutcher, 1985) indicate that NGF-like activity increases in adult hippocampus after fimbria transection. In the adult, Korsching et al. (1986) observed a small, transient $40 \%$ increase in NGF in the hippocampus 2 weeks after fimbria transection. This suggests that, in the adult, the regulation could be at the translational level or that NGF protein accumulates in the adult hippocampus subsequent to the degeneration of the axons that normally remove it.

In the adult periphery, chemical sympathectomy resulted in a marked increase in target-organ NGF, in agreement with previous data (Ebendal et al., 1983; Yap et al., 1984; Kanakis et al., 1985; Korsching and Thoenen, 1985). As in the adult CNS, NGF mRNA levels did not change similarly, suggesting that NGF protein accumulates following the removal of the retrograde axonal transport system, that there is an early transient rise in NGF mRNA, or that the rate of NGF synthesis increased.

In the neonate, however, fimbria transection results in an increase in both NGF mRNA and protein, suggesting either regulation at the transcriptional level or increased stability of NGF mRNA. Either mechanism indicates that an initial compensatory increase in NGF mRNA levels occurred in response to the decreased cholinergic innervation. The return to control levels $30 \mathrm{~d}$ after fimbria transection further implies a subsequent down-regulation, possibly due to compensatory reinnervation from remaining fibers, likely to be noncholinergic (see Fig. 1, $D, E)$, that sprout to fill the vacant postsynaptic sites.

Thus, NGF expression in the neonatal CNS may be specifically regulated by the level of afferent innervation, as has been observed for NGF expression in the adult iris, both in vivo and when transplanted to the anterior eye chamber (Ebendal et al., $1980,1983)$. The difference in control of NGF expression between the CNS and periphery, as well as the difference between neonatal and adult CNS (Whittemore et al., 1986) may be agerelated, with neonatal neurons showing greater plasticity to respond to an altered cellular environment.

\section{References}

Aviv, H., and P. Leder (1972) Purification of biologically active globin messenger RNA by chromatography on oligo-thymidylic acid-cellulose. Proc. Natl. Acad. Sci. USA 69: 1408-1412.

Barde, Y.-A., D. Edgar, and H. Thoenen (1983) New neurotrophic factors. Annu. Rev. Physiol. 45: 601-612.

Berg, D. K. (1984) New neuronal growth factors. Annu. Rev. Neurosci. 7: $149-170$.

Björklund, A., and U. Stenevi (1981) In vivo evidence for a hippocampal neurotrophic factor specifically released on septal deafferentation. Brain Res. 229: 403-428.

Björklund, A., B. Bjerre, and U. Stenevi (1974) Has nerve growth factor a role in the regeneration of central and peripheral catecholaminergic neurons? In Dynamics of Denervation and Growth in Neu- rons, K. Fuxe, L. Olson, and Y. Zotterman, eds., pp. 309-409, Pergamon, Oxford, U.K.

Chirgwin, J., A. Aeyble, R. McDonald, and W. Rutter (1979) Isolation of biologically active ribonucleic acid from sources enriched in ribonuclease. Biochemistry 18: 5294-5299.

Collins, F., and K. A. Crutcher (1985) Neurotrophic activity in the adult rat hippocampal formation: Regional distribution and increase after septal lesions. J. Neurosci. 5: 2809-2814.

Coons, A. H. (1958) Fluorescent antibody methods. In General $\mathrm{Cy}$. tochemical Methods, J. F. Danielli, ed., pp. 399-422, Academic, New York.

Cotman, C. W., and J. V. Nadler (1978) Reactive synaptogenesis in the hippocampus. In Neuronal Plasticity, C. W. Cotman, ed., pp. 227-272, Raven, New York.

Cotman, C. W., M. Nieto-Sampedro, and E. W. Harris (1981) Synapse replacement in the nervous system of adult vertebrates. Physiol. Rev. 61: 684-784.

Cowan, W. M., J. W. Fawcett, D. D. M. O'Leary, and B. Stanfield (1984) Regressive events in neurogenesis. Science 227: 1258-1265.

Crawford, G. D., L. Correa, and P. Salvaterra (1982) Interactions of monoclonal antibodies with mammalian choline acetyltransferase. Proc. Natl. Acad. Sci. USA 79: 7031-7035.

Crutcher, K. A., and F. Collins (1982) In vitro evidence for two distinct hippocampal growth factors: Basis of neuronal plasticity? Science 217: $67-68$.

Crutcher, K. A., L. Brothers, and J. N. Davis (1979) Sprouting of sympathetic nerves in the absence of afferent input. Exp. Neurol. 66: $778-783$.

Ebendal, T., L. Olson, Å. Seiger, and K.-O. Hedlund (1980) Nerve growth factors in the rat iris. Nature 286: $25-28$.

Ebendal, T., L. Olson, and $\AA$. Seiger (1983) The level of nerve growth factor as a function of innervation. Exp. Cell Res. 148: 311-317.

Frotscher, M., and C. Leranth (1985) Cholinergic innervation of the rat hippocampus as revealed by choline acetyltransferase immunocytochemistry: A combined light and electron microscope study. J. Comp. Neurol. 293: 237-246.

Gage, F. H., and A. Björklund (1986) Enhanced graft survival in the hippocampus following selective denervation. Neuroscience 17: 8998.

Gage, F. H., A. Björklund, and U. Stenevi (1984) Denervation releases a neuronal survival factor in adult rat hippocampus. Nature 308 . $637-639$

Gnahn, H., F. Hefti, R. Heumann, M. E. Schwab, and H. Thoenen (1983) NGF-mediated increase of choline acetyltransferase (ChAT) in the neonatal rat forebrain: Evidence for a physiological role of NGF in the brain? Dev. Brain Res. 9: 45-52.

Hefti, F. (1986) Nerve growth factor promotes survival of septal cholinergic neurons after fimbrial transections. J. Neurosci. 6: 21552162.

Hefti, F., A. Dravid, and J. Hartikka (1984) Chronic intraventricular injections of nerve growth factor elevate hippocampal choline acetyltransferase activity in adult rats with partial septohippocampal lesions. Brain Res. 293: 305-311.

Houser, C. R., G. D. Crawford, R. P. Barber, P. M. Salvaterra, and J. E. Vaughn (1983) Organization and morphological characteristics of cholinergic neurons: An immunological study with a monoclonal antibody to choline acetyltransferase. Brain Res. 266: 97-119.

Kanakis, S. J., C. E. Hill, I. A. Hendry, and D. J. Watters (1985) Sympathetic neuronal survival factors change after denervation. Dev. Brain Res. 20: 197-202.

Kamovski, M. J., and L. Roots (1964) A "direct-coloring" thiocholine method for cholinesterase. J. Histochem. Cytochem. 12: 219-221.

Korsching, S., and H. Thoenen (1985) Treatment with 6-hydroxydopamine and colchicine decreases nerve growth factor levels in sympathetic ganglia and increases them in the corresponding target tissues. J. Neurosci. 5: 1058-1061.

Korsching, S., G. Auberger, R. Heumann, J. Scott, and H. Thoenen (1985) Levels of nerve growth factor and its mRNA in the central nervous system of the rat correlate with cholinergic innervation. EMBO J. 4: $1389-1393$.

Korsching S., R. Heumann, H. Thoenen, and F. Hefti (1986) Cholinergic denervation of the hippocampus by fimbria lcsion lcads to a transient accumulation of NGF without change in NGF mRNA content. Neurosci. Lett. 66: 175-180.

Levi-Montalcini, R., and P. U. Angeletti (1968) Nerve growth factor. Physiol. Rev. 48: 534-569. 
Lewis, E. R., and C. W. Cotman (1980) Mechanisms of septal lamination in the developing hippocampus revealed by outgrowth of fibcrs from septal implants. I. Positional and temporal factors. Brain Res. 196: 307-330.

Loy, R., and R. Y. Moore (1977) Anomalous innervation of the hippocampal formation by peripheral sympathetic axons following mechanical injury. Exp. Neurol. 57: 645-650.

Lärkfors, L., and T. Ebendal (1987) Highly sensitive enzyme immunoassays for $\beta$-nerve growth factor. J. Immunol. Meth. (in press).

Manthorpe, M., M. Nieto-Sampedro, S. D. Skaper, E. R. Lewis, G. Barbin, F. M. Longo, C. W. Cotman, and S. Varon (1983) Neurotrophic activity in brain wounds of the developing rat. Correlation with implant survival in the wound cavity. Brain Res. 267: 47-56.

Markey, K. A., S. Kondo, I. Shenkman, and M. Goldstein (1980) Purification and characterization of tyrosine hydroxylase from a clonal phaeochromocytoma ccll linc. Mol. Pharmacol. 17: 79-85.

Mårtenson, R., and A. Björklund (1984) Low-power photography in the fluorescence microscope using an automatic dark-field condenserscanner. In Handbook of Chemical Neuroanatomy. Vol. 2: Classical Transmitters in the CNS, Part I, A. Björklund and T. Hökfelt, eds., pp. 380-386, Elsevier, Amsterdam.

Minty, A. J., M. Caravatti, K. Benoit, A. Cohen, P. Daubas, A. Weydert, F. Gros, and M. E. Buckingham (1981) Mouse actin messenger RNAs. Construction and characterization of a recombinant plasmid molecule containing a complementary transcript of mouse $\alpha$-actin mRNA. J. Biol. Chem. 286: 1008-1014.

Mobley, W. C., J. L. Rutkowski, G. I. Tennekoon, K. Buchannan, and M. V. Johnston (1985) Choline acetyltransferase activity in striatum of neonatal rats increased by nerve growth factor. Science 229: 284287.

Needels, D. L., M. Nieto-Sampedro, S. R. Whittemore, and C. W. Cotman (1985) Neuronotrophic activity for ciliary neurons: Induction following injury to the brains of neonatal, adult and aged rats. Dev. Brain Res. 18: 275-284.

Nieto-Sampedro, M., and C. W. Cotman (1985) Growth factor induction and temporal order in central nervous system repair. In Synaptic Plasticity, C. W. Cotman, ed., pp. 407-455, Guilford, New York.

Nieto-Sampedro, M., E. R. Lewis, C. W. Cotman, M. Manthorpe, S. D. Skaper, G. Barbin, F. M. Longo, and S. Varon (1982) Brain injury causes a time-dependent increase in neuronotrophic activity at the lesion site. Science 217: 860-861.

Nieto-Sampedro, M., S. R. Whittemore, D. L. Needels, J. Larsen, and C. W. Cotman (1984) The survival of brain transplants is enhanced by extracts of injurcd brain. Proc. Natl. Acad. Sci. USA 81: 62506254.

Schwab, M. E., U. Otten, Y. Agrid, and H. Thoenen (1979) Nerve growth factor (NGF) in the rat CNS: Absence of specific retrograde axonal transport and tyrosine hydroxylase induction in the locus coerulcus and substantia nigra. Brain Res. 168: 473-483.

Scott, J., M. Selby, M. Urdea, M. Quiroga, G. I. Bell, and W. J. Rutter (1983) Isolation and nucleotide sequence of a cDNA encoding the precursor of mouse nerve growth factor. Nature 302: 538-540.

Seiler M., and M. E. Schwab (1984) Specific retrograde transport of nerve growth factor (NGF) from neocortex to nucleus basalis in the rat. Brain Res. 300: 33-39.

Shelton, D. L., and L. F. Reichardt (1984) Expression of the $\beta$-nerve growth factor gene correlates with the density of sympathetic innervation in effector organs. Proc. Natl. Acad. Sci. USA 81: 7951-7955.

Shelton, D. L., and L. F. Reichardt (1986) Studies on the expression of $\beta$ nerve growth factor (NGF) gene in the central nervous system: Level and regional distribution of NGF mRNA suggest that NGF functions as a trophic factor for several distinct populations of neurons. Proc. Natl. Acad. Sci. USA 83: 2714-2718.

Stenevi, U., and A. Björklund (1978) Growth of vascular sympathetic axons into the hippocampus after lesions of the septo-hippocampal pathway: A pitfall in brain lesion studies. Neurosci. Lett. 7:219-224.

Stoeckel, K., C. Gagnon, G. Guroff, and H. Thoenen (1976) Purification of nerve growth factor antibodies by affinity chromatography. J. Neurochem. 26: 1207-1211.

Storm-Mathisen, J., and T. W. Blacksted (1964) Cholinesterase in the hippocampal region. Acta Anat. (Basel) 56: 216-253.

Thoenen, H., and Y.-A. Barde (1980) Physiology of nerve growth factor. Physiol. Rev. 60: 1284-1335.

Toniolo, G., S. B. Dunnett, F. Hefti, and B. Will (1985) Acetylcholinerich transplants in the hippocampus: Influence of intrinsic growth factors and application of nerve growth factor on choline acetyltransferase activity. Brain Res. 345: 141-146.

Wainer, B. H., A. I. Levey, E. J. Mufson, and M.-M. Mesulan (1984) Cholinergic systems in mammalian brain identified with antibodies against choline acetyltransferase. Neurochem. Int. 6: 163-182.

Whittemore, S. R., M. Nieto-Sampedro, D. L. Needels, and C. W. Cotman (1985) Neuronotrophic factors for mammalian brain neurons: Injury induction in neonatal, adult and aged rats. Dev. Brain Res. 20: 169-178.

Whittemore, S. R., T. Ebendal, L. Lärkfors, L. Olson, Å. Seiger, I. Strömberg, and H. Persson (1986) Developmental and regional expression of $\beta$ nerve growth factor messenger RNA and protein in the rat central nervous system. Proc. Natl. Acad. Sci. USA 83: 817821.

Winer, B. J. (1971) Statistical Principles in Experimental Design, McGraw-Hill, New York.

Yap, H. B., I. A. Hendry, C. E. Hill, and D. J. Watters (1984) Effects of cardiac denervation on levels of neuronal survival factors for cultured autonomic neurons. Dev. Brain Res. 12: 154-157. 